\title{
LOS SENTIDOS (DES)CENTRADOS DEL TRABAJO: HACIA UNA RECONSTRUCCIÓN DE LOS ITINERARIOS TÍPICOS DELINEADOS POR JÓVENES
}

EUGENIA ROBERTI*

\begin{abstract}
RESUMEN
El artículo aborda la constitución de las trayectorias laborales de jóvenes varones de un barrio periférico. El planteo teórico-metodológico parte de concebir a las trayectorias como un punto de cruce entre lo estructural y lo biográfico, entendiendo que los procesos de transición lineal de los jóvenes se han resquebrajado y requieren de miradas analíticas que consideren las múltiples esferas de la vida. Por esta razón, la investigación estudia las imbricaciones entre diversas esferas que, en el juego de sus interdependencias, dan forma a las trayectorias juveniles: la educación, la familia, el barrio y los grupos de pares. En esta línea, se elabora una tipología que surge del análisis empírico y que aparece como un hallazgo relevante para dilucidar la manera en que jóvenes de un mismo medio sociocultural configuran subjetividades y delinean recorridos divergentes.

PALABRAS CLAVE: CONDICIÓN JUVENIL, TRAYECTORIAS LABORALES Y VITALES, TIPOLOGÍA

* Licenciada en sociología, Magíster y Doctora en Ciencias Sociales por la Universidad Nacional de La Plata, Argentina. Becaria doctoral del Consejo Nacional de Investigaciones Científicas y Técnicas (CONICET), con sede en el Centro de Investigaciones Sociales (CIS-IDES/PREJET). E-Mail: eugenia.roberti@hotmail.com. El presente artículo forma parte de mi Tesis de Maestría, disponible en línea http://sedici.unlp.edu.ar.
\end{abstract}




\title{
OS SENTIDOS (DES) CENTRADOS DO TRABALHO: RUMO A UMA RECONSTRUÇÃO DOS ITINERÁRIOS TÍPICOS DELINEADOS POR JOVENS POBRES
}

\begin{abstract}
RESUMO
O artigo abrange a constituição das trajetórias laborais de homens jovens de um bairro periférico. A explicação teórico-metodológica começa a partir de conceber às trajetórias como um ponto de cruzamento entre o estrutural e o biográfico, entendendo que os processos de transição linear dos jovens se racharam e requerem de olhares analíticos que considerem as múltiplas esferas da vida. Por esta razão, a pesquisa estuda as imbricações entre diversas esferas que, no jogo das suas interdependências, moldam as trajetórias juvenis: a educação, a família, o bairro e os grupos de pares. Nesta linha, é elaborada uma tipologia que emerge da análise empírica e que aparece como uma descoberta relevante para dilucidar a maneira em que jovens do mesmo ambiente sociocultural configuram subjetividades e projetam caminhos divergentes.
\end{abstract}

\section{PALAVRAS CHAVE: CONDIÇÃO JUVENIL, TRAJETÓRIAS LABORAIS E VITAIS, TIPOLOGIA}

\section{(UN) FOCUSED SENSES OF WORK: TOWARDS A RECONSTRUCTION OF USUAL ITINERARIES OUTLINED BY POOR YOUTH}

\begin{abstract}
The article deals with the constitution of the career paths of young men from suburbs. From a theoretical-methodological perspective, these paths are conceived as a crossing point between structural and biographical aspects, understanding that the linear transition processes of young people have been fractured and need to be analyzed by critical points of view regarding a multiplicity of life fields. That is why this research is concerned about interdependence of multiple factors shaping youth paths: education, family, neighborhood and peers. A typology has been developed, showing up, based on an empirical analysis, as a prominent finding to elucidate the paths followed by young individuals from a same socio-cultural environment in order to configure subjectivities and draw divergent paths.
\end{abstract}

KEY WORDS: YOUTH CONDITION, LIFE AND CAREER PATHS, TYPOLOGY 


\section{LOS SENTIDOS DEL TRABAJO EN DISPUTA: ¿EL TRABAJO COMO FIN O MEDIO DE SUBJETIVACIÓN?}

EL PRESENTE APARTADO BUSCA comprender la inserción laboral mediante dimensiones subjetivas referidas a representaciones, aspiraciones y expectativas de los propios jóvenes. Partimos de la idea de que los cambios más profundos que afectaron al mundo del trabajo, en el último cuarto del siglo pasado, revelan nuevos significados y modos de actuar en las jóvenes generaciones. Para este abordaje, distinguimos dos niveles de análisis. Un sentido intrínseco que pone foco solo en la esfera laboral, donde el trabajo se presenta como un valor en sí mismo; desde este plano, se toma en consideración tanto los horizontes de posibilidad que delimitan el campo de las distintas actividades laborales a las que acceden los jóvenes, como también los anhelos y proyectos que involucran las formas que asume esa categoría más allá de su realización. El sentido extrínseco se define, en cambio, por la relación que el trabajo establece con otras esferas vitales, entendiendo que su distinción es esencialmente analítica debido a que las mismas están imbricadas y construyen en su conjunto las trayectorias juveniles.

\section{a) Los sentidos intrínsecos del trabajo: entre la experiencia vivida y la persistencia de un imaginario compartido}

Para abordar los sentidos intrínsecos que adquiere el trabajo en los jóvenes es fundamental remitirse en un primer momento a su significado genérico que revelamos bajo el interrogante: ¿Qué es el trabajo? Esta pregunta originó profundos silencios entre los entrevistados, primando como respuesta los términos «ayuda»y «plata». Si para un grupo de jóvenes este vínculo pareciera reducirse a un sentido instrumental que asocia el trabajo a una dimensión meramente económica; para otros, se relaciona con la necesidad, la sobrevivencia o el fin expreso del consumo al cumplir funciones relativas a la reproducción del grupo familiar. Más allá de estas primeras aproximaciones, se observa que el trabajo representa algo fundamental en la vida de los jóvenes, asociado muchas veces con la idea de progreso:

«si no trabajas, no sos nadie» (Mauricio, 24 años).

- ¿Del trabajo qué pensás, qué es un trabajo? 
- Una ayuda, ¿o no? Algo para progresar.

- ¿Por qué trabajás?

- Trabajo para estar más bien. No vas estar toda la vida arriba de un carro (Fermín, 19 años).

A partir de esta aproximación genérica al trabajo develamos la necesidad de diferenciar entre los horizontes de posibilidad (aquellas ocupaciones disponibles en el medio) y los proyectos laborales (posiciones ocupacionales imaginadas). Es importante diferenciar ambos niveles en tanto la trayectoria laboral se construye en sus intersticios y contradicciones. Precisamente, en el cuadro 1 identificamos a partir de diversos relatos una distinción entre los significados que adquiere el universo socio-ocupacional por el que transitan los jóvenes y aquellos sentidos asociados con situaciones anheladas, que derivaron en el uso de un conjunto de categorías antagónicas: cómodo/pesado; fijo/changa; me gusta/no me gusta; saber hacer/no saber hacer; ser alguien/no ser nadie; ligadas a la disyuntiva con estudios/sin estudios.

\section{CUADRO 1: LOS SENTIDOS INTRÍNSECOS DEL TRABAJO}

\begin{tabular}{|c|c|c|}
\hline $\begin{array}{l}\text { Cómodo/ } \\
\text { Pesado }\end{array}$ & $\begin{array}{l}\text { — ¿Qué es un buen trabajo? } \\
\text { — Un buen trabajo para mí... } \\
\text { que sea cómodo, que no sea } \\
\text { muy pesado, por eso yo vengo } \\
\text { a estudiar, porque trabajaba de } \\
\text { albañil y es pesado y, bueno, } \\
\text { tenés que sufrir en ese sentido } \\
\text { (Gustavo, } 18 \text { años). }\end{array}$ & $\begin{array}{l}\text { — ¿Ese laburo te gusta? } \\
\text { ¿Preferís laburar de otra cosa? } \\
\text { — El laburo es pesado, } \\
\text { pesadísimo, de lo más pesado } \\
\text { que hay, pero otra no queda } \\
\text { (Darío, } 26 \text { años). }\end{array}$ \\
\hline Fijo/Changa & $\begin{array}{l}\text { - Capaz que no nos llaman un } \\
\text { día, una semana sin laburo, y la } \\
\text { otra semana sí ... } \\
\text { - ¿Qué entendés por «trabajo } \\
\text { fijo»? } \\
\text { — Un laburo de toda la vida, } \\
\text { un laburo que estás ahí toda la } \\
\text { vida (Mario, } 16 \text { años). }\end{array}$ & $\begin{array}{l}\text { — ¿Y después qué otros } \\
\text { trabajos tuviste? } \\
\text { — Ninguno más... changuitas } \\
\text { de cortar pasto, podar árboles, } \\
\text { entrar tierra y también } \\
\text { escombros. Después trabajo, } \\
\text { así, de albañil (Marcelo, } 17 \\
\text { años). }\end{array}$ \\
\hline $\begin{array}{l}\text { Me gusta/ } \\
\text { No me gusta }\end{array}$ & $\begin{array}{l}\text { - Yo quiero conseguir un } \\
\text { laburo, así de ayudante, de lo } \\
\text { que sea, y después con el } \\
\text { tiempo recibirme del laburo } \\
\text { que me gusta. } \\
\text { — ¿Recibirte en qué sentido? } \\
\text { - Así, como ser un maestro } \\
\text { mayor de obra (Mauricio, } 24 \\
\text { años). }\end{array}$ & $\begin{array}{l}\text { — ¿Cuál es la característica } \\
\text { más importante de un trabajo? } \\
\text { - Que te guste. Porque si vas } \\
\text { a hacer algo que no te gusta, no } \\
\text { vas a ir, y no lo vas a hacer con } \\
\text { ganas y lo vas a hacer mal. Y te } \\
\text { van a echar. O no vas a querer } \\
\text { ir (Lautaro, } 18 \text { años). }\end{array}$ \\
\hline
\end{tabular}




\begin{tabular}{|c|c|c|}
\hline $\begin{array}{c}\text { Saber hacer/ } \\
\text { No saber } \\
\text { hacer }\end{array}$ & $\begin{array}{l}\text { — El colegio no me digas si lo } \\
\text { quería seguir porque, si me } \\
\text { preguntás, te digo que no. Pero } \\
\text { sí, lo quiero terminar } \\
\text { — ¿Por qué? } \\
\text { — Así tengo un buen trabajo } \\
\text { — ¿Qué es un «buen trabajo»? } \\
\text { — Tener un buen sueldo, es } \\
\text { saber algo, un oficio, estar en } \\
\text { blanco ... (Marcelo, } 17 \text { años). }\end{array}$ & $\begin{array}{l}\text { — ... empezamos a hacer un } \\
\text { par de changas de electricidad; } \\
\text { después nos tocó una obra de } \\
\text { plomería... } \\
\text { — ¿Todo con tu papá? } \\
\text { — Sí, una vez que más o } \\
\text { menos aprendí, me largué... } \\
\text { Antes capaz como estaba } \\
\text { laburando con mi viejo me } \\
\text { preguntaban si quería... «no» } \\
\text { dije, por vergüenza o por } \\
\text { miedo de no saber nada } \\
\text { (Herlo, } 16 \text { años). }\end{array}$ \\
\hline $\begin{array}{l}\text { Ser alguien/ } \\
\text { No ser nadie }\end{array}$ & $\begin{array}{l}\text { - Empecé el colegio para } \\
\text { poder terminarlo, así el día de } \\
\text { mañana poder ser alguien en el } \\
\text { futuro y, bueno, tener buena } \\
\text { salida laboral también } \\
\text { (Germán, } 18 \text { años). }\end{array}$ & $\begin{array}{l}\text { — ¿Qué lugar que ocupa el } \\
\text { trabajo en tu vida? } \\
\text { - Y lo primero es el trabajo. } \\
\text { Si no trabajás no sos nadie... } \\
\text { Tuve una época que no } \\
\text { laburaba pero cuando empecé a } \\
\text { laburar me di cuenta que el } \\
\text { trabajo es importante } \\
\text { (Mauricio, } 24 \text { años). }\end{array}$ \\
\hline
\end{tabular}

Como muestra este cuadro, las ocupaciones que realizan los jóvenes involucran fundamentalmente el trabajo manual y no calificado, al que caracterizan como «pesado». Los jóvenes entrevistados relatan pasajes cortos por diversas ocupaciones que no siempre califican para la adquisición de una práctica en un oficio o actividad determinada, impidiendo el despliegue de una trayectoria acumulativa. La duración de sus experiencias laborales suelen ser muy breves, la mayoría de las veces bajo la modalidad de «changas»; es decir, trabajos esporádicos, irregulares, de tiempo parcial que se realizan de forma recurrente.

Frente a la inestabilidad de sus inserciones ocupacionales, los entrevistados establecen una distinción respecto a aquellas experiencias laborales anheladas, asociadas con la estabilidad y la regulación del tiempo social que el empleo otorga: «un trabajo fijo que vos sabes que laburas todos los días» (Sebastián, 27 años). Incluso, las nuevas generaciones perciben como atributo prioritario el hecho de «estar en blanco», fundamentalmente porque casi ninguno de estos jóvenes accedió alguna vez a una ocupación de estas características.

En el marco de un mercado laboral que les deja pocas posibilidades para su inserción — «otra no queda»-, los entrevistados delinean múltiples estrategias frente a la falta de oportunidades que les impone su medio. En base a estas experiencias de rebusque, que implica un 
saber «arreglárselas», los jóvenes apuntan a obtener «cualquier laburo, mientras que me pague...» (Jeremías, 20 años); «que tenga sueldo fijo, ya te trabajo de cualquier cosa» (Herlo, 16 años). Esta disposición a trabajar de «lo que venga» se manifiesta en una suerte de identidad laboral indefinida, donde los jóvenes aspiran acceder a cualquier clase de trabajo para sobrevivir.

Si en un primer momento el vínculo que establecen los jóvenes con el trabajo pareciera reducirse a la privación o supervivencia; al ahondar en sus sentidos ideales hallamos, en contraposición, un horizonte simbólico que se desliza hacia un conjunto amplio de significaciones que abarca desde la utilidad social («[no me gusta] estar al pedo». Ramiro, 29 años), el divertimento («un ambiente [laboral] divertido, más alegre». Elio, 18 años), hasta la realización personal y la obligación moral («las cosas para tenerlas, te las tenés que salir a ganar». Felipe, 19 años). De este modo, los jóvenes buscan algo más que un intercambio económico o una fuente de ingresos, anhelan poder identificarse con una ocupación — «que te guste»—; involucrarse en el aprendizaje de calificaciones, habilidades y competencias requeridas en el mundo del trabajo — «que yo lo sepa hacer»; «saber algo»—. En este contexto, es que la actividad laboral comienza a ser vista como una fuente de reconocimiento social — «ser alguien».

Por consiguiente, en los relatos juveniles lo que está en disputa no es el significado del trabajo, asimilado aún con el empleo asalariado, sino más bien sus modos de actuar «changas», frente a un mercado laboral que no les deja mucho margen para su inserción. En un contexto de inestabilidad laboral los sentidos que los jóvenes establecen con el trabajo se orientan entonces hacia un carácter instrumental, apareciendo el salario como el único criterio determinante para empezar o abandonar una ocupación.

Ahora bien, la definición de un «buen salario» presenta significados diversos: ganar una remuneración justa («no fui más porque me pagaban poco»), disponer de ingresos que no fluctúen mensualmente («que tenga sueldo fijo») y obtener recursos para acceder a los bienes necesarios en ese momento de sus vidas («te agarra la edad que querés salir, que necesitás plata y laburás»).

- ¿Cuál es la característica más importante de un trabajo?

- Que me paguen lo máximo posible... y sí, la plata. Todos nos fijamos en la plata, todos vamos a trabajar por la plata. Te quiero decir, no que sea lindo, que esté cómodo... yo voy a trabajar por la 
plata y así cubrirme mis necesidades, las mías, las de mis hijos... (Sebastián, 27 años).

Para estos jóvenes que desarrollan actividades situadas en el extremo de la informalidad, se observa que lo que se ha desdibujado es la posibilidad de desplegar un sentido simbólico del trabajo - búsqueda de reconocimiento, gratificación, desarrollo de carrera-, pasando la dimensión económica a ocupar el primer plano. En efecto, la identificación con el mundo laboral resulta problemática principalmente porque los contenidos y saberes de las tareas desarrolladas no constituyen elementos significativos en la conformación de una subjetividad vinculada al trabajo. Lo laboral pierde fuerza como referente identitario frente a la clase de ocupación a la que pueden acceder los jóvenes dentro de sus horizontes de posibilidad. Se establece así un vínculo instrumental con el trabajo, el cual aparece como una empresa individual, orientada a satisfacer necesidades propias o del núcleo familiar más cercano (Freytes Frey, 2009).

No obstante, de lo enunciado no se deduce que la esfera laboral pierda importancia en la vida de los jóvenes. Por el contrario, observamos la necesidad de atender al imaginario simbólico de cada joven, donde se juegan nuevos sentidos a la luz de las expectativas, proyectos y anhelos laborales que se configuran en función de sus condiciones socioeconómicas adscriptas. Desde este lugar, las formas de anticipación al devenir cumplen un rol fundamental a la hora de develar los horizontes de posibilidad imaginables que despliegan los jóvenes en la constitución de sus itinerarios (Longo, 2012). En otros términos, los posibles rumbos de futuro se interpretan como aquellas salidas laborales que los jóvenes perciben a su alcance; expresión de las formas de apropiación que hacen de su contexto de oportunidad.

De allí que, a través de los relatos se puede evidenciar un cruce entre el campo de lo posible y el orden de lo deseable, que tiene como resultado la conformación de tres universos socio-ocupacionales distintos en lo que respecta al proyecto biográfico laboral (Pries, 1999). ${ }^{1}$

1 La noción de proyecto biográfico-laboral se entiende como una proyección hacia el futuro de lo que para el individuo es lo normal, lo deseable, lo alcanzable, lo realizable y, al mismo tiempo, es producto de las experiencias de vida anteriores. El concepto intenta, de este modo, integrar dos dimensiones: en el eje del tiempo entrelaza el pasado, presente y futuro; $y$, en el eje de la relación individuo-sociedad, integra la estruc- 
En un extremo, si para un grupo de jóvenes la meta a alcanzar se ubica en el ámbito profesional o en la instalación en un oficio de forma autónoma; en el otro extremo, para otros jóvenes su futuro laboral parece quedar reducido a los trabajos realizados por sus familiares y su círculo relacional o, por el contrario, librado a la incertidumbre y a la indefinición de un proyecto ocupacional (véase cuadro 2).

- Los jóvenes que proyectan un futuro ligado al ejercicio de funciones profesionales o insertos en un oficio de forma independiente, y buscan establecer una ruptura con la cultura parental.

- Los jóvenes cuyas expectativas futuras no visualizan mejoras en su trayecto laboral, adquiriendo protagonismo los mecanismos de reproducción social. Aquí, las expectativas de posicionamiento social se remiten a alcanzar las ocupaciones paternas o, por el contrario, se limitan a esperar la repetición de sus actuales condiciones de existencia, dejando entrever una actitud pasiva hacia el devenir. Si bien el futuro parece como un destino inevitable, depositan aspiraciones de ascenso social en sus hijos.

- Los jóvenes que no visualizan ninguna forma de inserción laboral, persistiendo la vaguedad de las metas y la imposibilidad de proyectarse en el futuro. En este sentido, juzgan el proyecto laboral como impredecible e incierto; o, en contraposición, presentan aspiraciones que parecen desmesuradas en relación a su contexto de oportunidad, asumiendo sus planes un carácter utópico.

\section{b) Los sentidos extrínsecos: el descentramiento del mundo laboral}

A diferencia de los sentidos intrínsecos, los sentidos extrínsecos del trabajo se articulan y constituyen en interacción con los proyectos de otros ámbitos de la vida. Las distintas esferas vitales de los jóvenes, separadas mediante un ejercicio analítico, interactúan dando conjuntamente significado a las decisiones y proyecciones laborales. Desde este lugar, las ocupaciones informales son un recurso para alcanzar objetivos que se juegan por fuera del dominio laboral.

Así, uno de los hallazgos de la investigación refiere a esta centralidad relativa que asume la esfera laboral. Frente a las tesis que postulan el «fin del trabajo» (Offe, 1985; Rifkin, 1996; Gorz, 1997), sostenemos que el mundo laboral no ha perdido importancia en la vida de los jóvenes, sino que adopta nuevas prácticas y sentidos que deben

tura social histórica como base y limitación de planes y acciones individuales. 
aprehenderse en su relación con otras esferas vitales significativas. En efecto, sostenemos que el trabajo sigue siendo un espacio privilegiado de conformación de subjetividades e identidades aunque, como señala Svampa (2000), no resulte el único ni el central. Razón por la cual consideramos necesario analizar el vínculo que los jóvenes establecen con el trabajo a partir de una configuración subjetiva compleja que tome en cuenta su articulación con diversos mundos de la vida.

En correspondencia con los objetivos que guían al artículo, presentamos a continuación una tipología ${ }^{2}$ sobre los sentidos extrínsecos del trabajo que busca comprender el modo en que se configuran las relaciones de las nuevas generaciones con el mundo laboral, atendiendo a la imbricación de las múltiples esferas de la vida que diversifican las trayectorias juveniles. Desde este lugar, se busca iluminar la relación juventud-trabajo considerando las esferas vitales más importantes, desde la propia mirada de los entrevistados: la educación, la familia y los grupos de pares/el barrio.

CUADRO 2: TIPOLOGÍA DE LOS SENTIDOS EXTRÍNSECOS DEL TRABAJO

\begin{tabular}{|l|l|l|l|l|}
\hline & $\begin{array}{c}\text { Esfera } \\
\text { vital } \\
\text { predomi- } \\
\text { nante }\end{array}$ & $\begin{array}{c}\text { Articulación } \\
\text { trabajo y esferas } \\
\text { vitales }\end{array}$ & $\begin{array}{c}\text { Horizonte } \\
\text { temporal de } \\
\text { realización }\end{array}$ & $\begin{array}{c}\text { Proyecto } \\
\text { laboral }\end{array}$ \\
\hline $\begin{array}{l}\text { Trayectorias } \\
\text { escolarizadas }\end{array}$ & Escuela & $\begin{array}{l}\text { Trayectoria socio- } \\
\text { ocupacional de } \\
\text { ascenso }\end{array}$ & A largo plazo & $\begin{array}{l}\text { Acorde a la } \\
\text { formación }\end{array}$ \\
\hline $\begin{array}{l}\text { Trayectorias } \\
\text { reproductivas }\end{array}$ & Familia & $\begin{array}{l}\text { Independencia } \\
\text { residencial }\end{array}$ & $\begin{array}{l}\text { A mediano } \\
\text { plazo }\end{array}$ & $\begin{array}{l}\text { Reproductiva } \\
\text { o intergene- } \\
\text { racional }\end{array}$ \\
\hline $\begin{array}{l}\text { Trayectorias } \\
\text { territorializa- } \\
\text { das }\end{array}$ & $\begin{array}{l}\text { Grupo de } \\
\text { Pares/ } \\
\text { Barrio }\end{array}$ & $\begin{array}{l}\text { Consumos } \\
\text { juveniles }\end{array}$ & Inmediato & $\begin{array}{l}\text { Indefinido o } \\
\text { utópico }\end{array}$ \\
\hline
\end{tabular}

2 La elaboración de tipologías habilita un análisis de las regularidades y diferenciaciones que se constituyen en las trayectorias de jóvenes pertenecientes a un mismo medio sociocultural. Cabe advertir que en toda tipología se resaltan aquellos elementos distintivos a partir de los cuales se conforma la clasificación. En la elaboración de una tipificación se combinan así variables diversas que se ajustan más o menos a cada situación; para nuestro análisis tomamos en cuenta las esferas biográficas más significativas, los proyectos futuros y los horizontes de realización que delinean los jóvenes. 
La tipología elaborada explora los sentidos extrínsecos a partir del mayor predominio que los jóvenes confieren a alguna de estas esferas de la vida, vinculada con las expectativas que se configuran en torno a ellas como ámbitos de subjetivación y realización personal. Estos sentidos descentrados, que encuentran su explicación en los cambios acaecidos en el mundo laboral desde fines del siglo XX, manifiestan que los jóvenes del Aluvión no constituyen una subjetividad en torno al trabajo; por el contrario, el mismo adopta un carácter meramente instrumental que se orienta a la realización de otros proyectos vitales dentro de sus horizontes de posibilidad. En consecuencia, la esfera laboral presenta un papel central como eje articulador del sentido que adquieren otros ámbitos de la vida para los jóvenes. Como explica Saraví, «el trabajo no constituye un fin en sí mismo, sino un medio, y es la condición de medio para el logro de otros fines lo que le otorga importancia» (2009:233).

En este punto, es necesario considerar las distintas constelaciones de sentidos otorgados al trabajo por los jóvenes y la manera en que ubican subjetivamente a la actividad laboral, en el marco de un proyecto vital más amplio (Guerra Ramírez, 2008). Precisamente, los itinerarios juveniles se encuentran enmarcados en un contexto de oportunidades socialmente estructurado, a la vez que abierto a las preferencias y opciones adoptadas a nivel individual (Jacinto, 2010): las experiencias particulares de cada joven $-\mathrm{y}$ los sentidos, estrategias o decisiones que implican - permiten comprender así las singularidades de cada trayectoria, atendiendo a la particular articulación de las diferentes esferas vitales.

En las próximas páginas abordamos el modo en que se configura cada una de estas «encrucijadas típicas», prestando especial atención a la centralidad relativa que adquiere el trabajo en los procesos de subjetivación de acuerdo a cada esfera vital, según la tipología elaborada. A modo de ilustración se reconstruye, al finalizar el análisis de cada una de estas esferas, una historia de vida típica.

A los efectos de clarificar esta construcción analítica, a continuación realizamos una descripción e identificación de los tres tipos de trayectorias que delinean los jóvenes.

En las trayectorias escolarizadas, se presentan aquellos casos típicos donde el sentido que adquiere el trabajo se encuentra subsumido a la esfera educativa. Si bien la etapa de escolarización se desarrolla de forma conjunta a las primeras experiencias laborales, obstaculizando el pasaje por la enseñanza media, los jóvenes reorientan sus 
aspiraciones - luego de experiencias educativas frustradas - buscando conciliar o abandonar una posición ocupacional en el intento por finalizar la escuela. La culminación de los estudios secundarios se entrelaza para este grupo de jóvenes con el proyecto a largo plazo de continuar una formación profesional u ocupacional.

Centrados subjetivamente en proyectos de formación, se plantean alcanzar una inserción de calidad con la obtención de sus credenciales educativas. Aunque la escuela adquiera una relevancia fundamental en el discurso de la mayoría de los jóvenes entrevistados, la particularidad de este grupo radica en que la finalización del ciclo obligatorio es un proyecto realizable, amparado por el mayor capital cultural y social de su grupo familiar de origen. Por otra parte, no desarrollan un sentido de pertenencia en el ámbito barrial y tampoco han conformado aún su propio proyecto familiar.

En las trayectorias reproductivas, el trabajo aparece vinculado con otra esfera vital prioritaria para los jóvenes: la familia. Principalmente son jóvenes que al momento de la entrevista no están asistiendo a un establecimiento educativo y se encuentran relegados hacia el espacio privado de su hogar. Frente a la ausencia de condiciones objetivas para desarrollar una trayectoria laboral acumulativa, adquiere relevancia los mecanismos de reproducción social. Aquí, las expectativas laborales se remiten a alcanzar las ocupaciones paternas o, por el contrario, se limitan a mantener las actuales condiciones laborales. Si bien el devenir aparece como un destino inevitable, la mayoría de estos entrevistados depositan sus esperanzas en lograr una movilidad intergeneracional.

En especial, para este grupo el trabajo aparece asociado con la conformación de la familia propia y, en consecuencia, con la consumación de una independencia residencial progresiva. El marco de esta estrategia vital más amplia, centrada en la constitución de la familia propia y la residencia independiente - en particular, su modo de realización en las primeras etapas-, forma parte de las condiciones de posibilidad de estos jóvenes en un horizonte temporal de mediano plazo.

Por último, se encuentra aquel grupo de jóvenes que delinean trayectorias territorializadas. Una de las formas más recurrentes que adopta la relación de los jóvenes con la actividad laboral reside en la disposición de ingresos para acceder a bienes de consumo que medien los vínculos con el grupo de pares. El consumo es un medio de realización temporal inmediato que permite a los jóvenes experimentar un conjunto de estéticas y prácticas significantes donde cobran forma los 
estilos juveniles; aquellos patrones de consumo cultural que funcionan como referentes de identificación compartidos.

En este tipo ideal, adquiere especial relevancia la pertenencia barrial. Las actividades cotidianas de estos jóvenes transcurren en general dentro de los límites geográficos acotados de su barrio; allí asisten a establecimientos educativos, salen a trabajar y pasan su tiempo libre. Librados a la indefinición e incertidumbre de su proyecto ocupacional, constituyen un itinerario errático con la escuela - sin alcanzar a vislumbrar su culminación-, al mismo tiempo, mantienen una relación conflictiva con el modelo familiar de origen - sin todavía haber conformado su propia familia-. Frente al resquebrajamiento de la relación de estos jóvenes con las instituciones tradicionales (trabajo, educación y familia), adquiere centralidad la conformación de una subjetividad en torno al barrio y los grupos de pares.

Más allá de esta clasificación, el trabajo representa en todos los casos una condición fundamental para la realización de proyectos, esperanzas y sueños que se juegan por fuera de la esfera laboral: los sentidos del trabajo responden a una orientación extrínseca, centrada en otros ámbitos como la familia, la escuela, el grupo de pares y el barrio. De este modo, la diversidad de significados que los jóvenes atribuyen al trabajo reveló un mundo amplio de sentidos, que se orientan hacia la realización de proyectos colectivos e individuales de variado horizonte temporal: la satisfacción de necesidades de consumo individual inmediatas; la mejora de las condiciones de vida familiar y el logro de la independencia residencial; la primacía de proyectos de formación profesional con vistas a alcanzar una movilidad socioocupacional.

\section{LAS PARADOJAS DEL SISTEMA ESCOLAR: LA CONFIGURACIÓN DE TRAYECTORIAS EDUCATIVAS ERRÁTICAS}

La descripción del itinerario educativo que delinean los jóvenes entrevistados asume un carácter errático; la etapa de instrucción suele ser breve y está signada por ciclos discontinuos que trazan un camino marcado por el abandono escolar y la alternancia institucional. Estos itinerarios escolares fragmentados se desarrollan, en algunos casos, desde edades muy tempranas.

- ¿El tema de los estudios cómo fue?

- Vagancia. Fue catastrófico directamente, empecé primero, segundo 
y ya tercero repetí [del primario...]. Arranqué de vuelta, y ya arranqué con pocas ganas. Las maestras me hacían pasar... Después no quise estudiar más. Iba a repetir 8 vo año y me fui a la mierda. Le dije a mi vieja que no iba a estudiar más y me puse a laburar (Ramiro, 29 años).

En términos generales, los jóvenes realizan una valoración positiva de la institución escolar, como un espacio de aprendizaje y crecimiento personal: «sirve un montón porque enseña mucho, te hace crecer» (Darío, 26 años). No obstante se observa, como plantea Jacinto (2006), una dificultad para nombrar entre los aprendizajes algún contenido por fuera de las competencias lingüísticas, orales y escritas: «yo no quiero saber nada, si yo ya sé leer y escribir» (Lautaro, 18 años). Desde esta mirada, la decisión de retomar o continuar el colegio se relaciona con la certificación que brinda esta institución, donde no son valorados los conocimientos instruidos sino «el papel» (título secundario) que habilitaría el acceso a un trabajo de calidad: «me anoté para ver si puedo cambiar de trabajo; terminar y con el secundario buscar otra cosa...» (Sebastián, 27 años). Como sintetiza el siguiente relato:

La escuela te ayuda a crecer como persona... Vendría a ser como el eje de tu vida, porque si nunca estudiaste, nunca hiciste nada, no vas a tener un laburo, porque si no sabés ni leer, ni escribir, es difícil conseguir laburo (Mauricio, 24 años).

Si bien todos los entrevistados tienen en su horizonte a la escuela secundaria, esta meta difícilmente se alcanza. El estudio aparece en los jóvenes bajo la forma de un «deber ser», manifiesto en la expresión «hay que estudiar», que no se condice con lo que sucede en sus prácticas cotidianas. Precisamente, la escuela no logra resolver la tensión entre urgencia y proyecto que se despliega en esa etapa de sus vidas; cristalizada en una lógica contradictoria entre la estrategia de reproducción a corto plazo y la estrategia de formación a largo plazo. Así, los jóvenes establecen de idas y vueltas con el colegio: entre el imaginario y lo posible, van trazando una trayectoria educativa errática.

Hay algo que se repite: todos regresan. Están un año y dejan antes de terminar el año, por trabajo, o lo que sea. Hay cuestiones más fuertes que no sé con qué tienen que ver, que los preexiste. Ellos quieren, pero no lo pueden hacer... (Ana, maestra escuela de adultos). 
Los jóvenes desertan del sistema educativo, en razón de que la escasez de ingresos de sus hogares los obliga a adelantar su entrada al mercado de trabajo, aún antes de completar su formación. Sin embargo, el abandono prematuro de la escuela no debe atribuirse exclusivamente al origen socioeconómico. Es necesario considerar también la capacidad de interpelación que tiene la institución escolar $-\mathrm{y}$ con ella la diversidad de expectativas y sentidos atribuidos a otras esferas de la vida - en la conformación de un proyecto vital y laboral.

Las connotaciones simbólicas que asume la escuela en los jóvenes, la ubican en un lugar relegado frente a otras esferas alternativas, que presentan una mayor incidencia en los procesos de subjetivación. Estos procesos se desarrollan en el marco de lo que Kessler (2010) denomina «una escolaridad de baja intensidad»; «al estudio no le daba bolilla» (Alejo, 29 años); «me empecé a portar mal y, bueno, después faltaba o me rateaba» (Gastón, 18 años); «de vagancia estaba, no me gustaba» (Jeremías, 20 años). Estas inconsistencias y debilidades dan lugar a una institución escolar que se encuentra imposibilitada para responder a aquellos significados tradicionales que la convirtieron en un lugar privilegiado de producción de las juventudes.

Se constituye así en una escuela acotada, que luego de los años iniciales comienza a perder su capacidad de interpelación, quedándose paulatinamente vacía de sentido. El «desastre» y el «aburrimiento» emergen como los sentimientos que permean la experiencia escolar y que denotan la incapacidad de la escuela para marcar a los sujetos (Saraví, 2009:306).

Frente a la pérdida de centralidad de la escuela se presentan ámbitos alternativos de identificación y subjetivación juvenil. Desde esta perspectiva, en la biografía de los jóvenes la constitución temprana de la familia propia es avalada por su contexto sociocultural, propiciando el retiro de la escuela y la búsqueda de una ocupación: «cuando me junté, a los 19 años, dejé la escuela para empezar a laburar» (Mauricio, 24 años). Otro argumento al que acuden algunos entrevistados para abandonar el colegio se vincula a las formas de sociabilidad que desarrollan con los grupos de pares, donde «la vagancia», «la calle, «la droga», adquieren preponderancia ante una institución escolar que no logra representarse como un espacio de socialización e integración juvenil. Esta fragilidad se expresa también en aquellos aprendizajes que generan desacuerdos y conflictos con la cultura juvenil, como se manifiesta en las frases: «en la calle se aprende más que en el colegio» 
(Nota de campo, $\mathrm{N}^{\mathrm{o}} 14$ ); «La calle me ayudó a saber bastantes cosas... que no aprendo en mi casa o en la escuela» (Herlo, 16 años).

Más allá de la importancia que adquiere el espacio público como instancia de socialización predilecta para algunos entrevistados (tipo ideal: trayectorias territorializadas), en ninguno de los relatos se presenta una valoración de la experiencia escolar como ámbito de sociabilidad, tampoco como un período de moratoria social, ya que los mismos ingresan tempranamente al mundo del trabajo y suelen contraer a menor edad obligaciones familiares (Margulis, 2008).

No era nuestra edad para buscar trabajo. Porque los chicos a esa edad no están trabajando, le están manteniendo los padres los estudios. Nosotros no tuvimos esa oportunidad de estudio, de formarnos... Yo lo hubiera hecho si hubiera tenido la oportunidad... ahora ya estoy grande, si no pienso en el trabajo... (Marcos, 23 años).

Como explica Tenti Fanfani (2000), la situación anterior coloca a los jóvenes en un dilema: el quedar al margen de la escuela, excluidos de las opciones de aprendizaje formal en un mundo que les exige cada vez más conocimientos; o enrolarse en un trayecto complicado y difícil de sostener para ellos y sus familias, del que no obtendrán ningún beneficio en el corto plazo en términos de movilidad social ascendente. Solo para aquel grupo de jóvenes en los que la esfera educativa adquiere una centralidad fundamental en la conformación de su subjetividad y en la formulación de un proyecto vital y laboral - donde las credenciales educativas desempeñan un papel decisivo en la identificación simbólica con las profesiones-, la permanencia en la escuela constituye una estrategia legítima frente al conjunto de trabajos irregulares, esporádicos y desprotegidos a los que usualmente logran acceder (tipo ideal: trayectorias escolarizadas). Como refleja la siguiente entrevista, en las biografías de estos jóvenes prima la actividad educativa sobre la laboral.

- ¿Si hoy en día te saldría un laburo y no podrías seguir estudiando qué valorarías?

- El estudio. Para mí es más importante el estudio, seguiría estudiando, eso seguro. Por más que salga otro trabajo, que me paguen... después si tenés otro trabajo ponele cuánto durás dos o tres meses, ya perdiste las ganas de estudiar, la posibilidad y van pasando los años (Elio, 18 años). 


\section{TRAYECTORIAS ESCOLARIZADAS: EL CASO DE ALEJO}

Alejo tiene 29 años de edad, desde que nació vive en el barrio. Sin embargo, su particular origen sociocultural revela un punto de inicio diferencial en la constitución de la trayectoria de este joven, como trasluce el siguiente relato: «yo vivo acá en el barrio pero, cómo te puedo decir, no me comporto como de un barrio, de un lugar muy marginal».

La trayectoria educativa de Alejo manifiesta también ciertos rasgos distintivos. Si bien concurrió a una escuela técnica ubicada en el casco urbano, no logró culminar allí sus estudios, comenzando una rotación por distintas instituciones de nivel medio. Así expresa el vínculo que mantuvo con la escuela: «en ese tiempo era chico y al estudio no le daba bolilla». Frente a una escolaridad de baja intensidad, su padre le planteó: «si vos dejás de estudiar, empezás a laburar». De este modo, comenzó a trabajar junto a él en el oficio de plomero: «lo seguí a mi viejo desde chico y ya sabía cómo era lo de plomería».

Durante un largo tiempo continúo trabajando de plomero junto a su padre, aunque intercaló esta actividad con «algunas changuitas más» (pinturería, jardinería, etcétera). Sin embargo, Alejo decide continuar un camino diferente al paterno en razón de la inestabilidad laboral que caracteriza a la actividad por cuenta propia: «hay días que uno tiene plata y otros días que no... Yo lo que busco es la continuidad en el trabajo, que todos los meses me paguen un sueldo».

En la actualidad, este joven trabaja como empleado de una empresa de seguridad privada. A pesar que, en un primer momento, señala: «es un sueldo fijo que uno lo tiene siempre», buscando alejarse de las vivencias de la generación precedente en lo que respecta a la incertidumbre laboral — «yo no quería pasar lo mismo»—; la regularidad salarial no implicó una continuidad ocupacional. La modalidad de tercerizar la contratación de personal, ha conllevado a constantes cambios en el recorrido laboral de Alejo, quien hoy en día transita por su cuarta empresa de seguridad con posibilidades de quedar finalmente efectivo. Más aún, esta forma de contratación ha provocado que, circunstancialmente, volviera al trabajo de plomería: «te tomaban por un tiempo..., las veces que me quedaba parado, hasta que agarraba otro [contrato], trabajaba con mi viejo haciendo lo que ya sabía».

Esta intermitencia ocupacional le ha impedido conciliar la actividad educativa con la laboral. Así, luego de transcurrir algunos años, retoma los estudios pero debe abandonarlos al ingresar en una empresa de seguridad: «no podía venir a estudiar», y prosigue: «el año pasado estaba en una empresa que, como no me dieron el horario, no fui más: 'no me voy a perder la escuela por ustedes'». 
Al momento que realizamos la entrevista, Alejo continúa trabajando como personal de seguridad pero acordó con la empresa para asistir al colegio durante los días de franco. De este modo, su trayectoria laboral se estructura en base a la escuela, proyectando un futuro ligado a la profesión policial. Aunque en otras entrevistas se hizo referencia al valor de la educación para conseguir un trabajo: «hoy en día, lo tengo que terminar sí o sí, obligado, para poder entrar [de policía]», en el relato de Alejo la institución escolar es el hilo conductor de su biografía: todo remite a la importancia de los estudios y su decisión de abandonarlos. Como se expresa en su relato, la institución educativa asume en la trayectoria de este joven un lugar esencial:

El colegio, para mí, es la base. Es como la casa, si no le hacés las bases seviene abajo... La escuela, es lo fundamental. La escuela, el trabajo y la familia. Hoy día la edad que tengo, yo tendría que estar disfrutando solamente de trabajar y tengo que acomodarme horarios para terminar de estudiar (Alejo, 29 años).

\section{b) Un acercamiento a la dimensión familiar: la configuración de trayectorias intergeneracionales}

La familia constituye un ámbito central de referencia y una dimensión esencial en la construcción social de las trayectorias juveniles. De hecho, un aspecto relevante de los trayectos intergeneracionales, radica en la similitud de las ocupaciones realizadas por padres e hijos. Los recorridos laborales no pueden ser leídos ni entendidos al margen de las historias de familia (Márquez, 2001). Los itinerarios por el mundo del trabajo expresan una condición familiar: oficios que se heredan, capacidades y habilidades que se transmiten y vínculos de parentesco que generan oportunidades.

En este punto, advertimos que el ingreso al mundo laboral de las nuevas generaciones se constituye a partir de un conjunto de prácticas no formalizadas que se desarrollan por medio de las redes familiares, a través de las cuales los jóvenes entran en contacto por primera vez con el trabajo. Esta socialización temprana conjuga los espacios de trabajo con los tiempos de la formación, al implicar una transmisión de saberes que se dan «en el seno de la familia de manera implícita y centrados en las interacciones en torno al proceso productivo mismo» (De Ibarrola, 2006:33): «lo aprendí en mi casa, trabajando con él [padre]» (Jeremías, 20 años). 
Por consiguiente, en tanto el grupo familiar constituye una de las primeras vías de ingreso y socialización en el trabajo, muchos de los jóvenes se encuentran realizando las mismas actividades que sus padres. De allí que las nuevas generaciones no vislumbren una diferencia en el itinerario laboral delineado, sino más bien una continuidad intergeneracional. En este sentido, la ocupación paterna se presenta como un camino «asegurado», una «herencia», que los jóvenes no siempre deciden continuar; no solo porque al interior de su universo socio-ocupacional se ubican dentro de las categorías de trabajos de carácter manual, pesados e inestables; sino principalmente porque son parte de las identidades heredadas, ligadas al origen social y familiar, de las cuales muchos de los jóvenes buscan diferenciarse.

- ¿Te gustaría tener los laburos que tienen tus papás?

- No, si ya los tengo.

- ¿Te gustaría algo diferente al laburo que tienen?

- Algo distinto, algo mejor (Juan, 19 años).

En esta búsqueda, algunos entrevistados intentan apartarse de aquellos trabajos que constituyen su campo laboral de posibilidad (albañil, ciruja, cooperativista, etcétera), al mismo tiempo que proyectan alcanzar una actividad que les permita una realización personal. Surge así en un grupo de jóvenes una identificación simbólica con las profesiones, que apela a otras imágenes relacionadas con mejores condiciones de trabajo, mayores gratificaciones económicas y la esperanza de una vida mejor. En contraposición, otros entrevistados no logran avizorar en su futuro más que una inestabilidad duradera, adquiriendo relevancia los mecanismos de reproducción social: las expectativas laborales futuras se remiten a alcanzar las ocupaciones paternas o, por el contrario, se limitan a replicar las actuales condiciones laborales (tipo ideal: trayectorias reproductivas).

Por consiguiente, el trabajo - al igual que la escuela - aparece asociado con un imaginario de movilidad socioocupacional, que difícilmente está al alcance de los jóvenes. En su lugar, la conformación de una familia propia y la consumación de una independencia residencial se presentan como alternativas dentro de sus horizontes de oportunidad. En esta dirección, la transición temprana hacia la autonomía familiar se percibe como una opción posible frente a otras esferas de integración, al formar parte de una experiencia cotidiana y socialmente aceptada dentro de su contexto sociocultural. Es en torno a estos 
proyectos realizables que algunos entrevistados conforman su subjetividad, donde la autonomía domiciliaria asume un carácter progresivo: cuarto propio, casilla en el fondo de la casa familiar, terreno y, más adelante, la casa de material; sueño que forma parte del conjunto de los jóvenes. Como expresa el relato de Marcos, aquí el trabajo se concibe como un medio para la realización de una estrategia vital más amplia, centrada en el mundo familiar.

- ¿Qué es el trabajo?

- El trabajo es aquello útil que te lleva a cumplir sueños, necesidades... Era lo que me iba a llevar progresar a mí. Pero hay otras cosas antes que el trabajo

- ¿Cuál es la característica más importante del trabajo?

- En sí lo económico me lleva a buscar otros trabajos. Para llegar a completar mi sueño: comprar mi terreno, hacerme mi casa. Eso me lleva a cambiar de trabajo... Busco otro trabajo que pueda disfrutar más de lo sociable y de mi familia, y que pueda ganar un poco más (Marcos, 23 años).

En este marco, la temprana constitución familiar aparece en los relatos como el evento vital más significativo, que ocasionó profundas reconfiguraciones en las biografías de los jóvenes al propiciar cambios en otras esferas de la vida: no solo en relación a la trayectoria escolar, donde los períodos de formación se ven interrumpidos con las responsabilidades de la edad adulta «cuando ella quedó embarazada tuve que dejar de estudiar para empezar a buscar un trabajo» (Alejo, 29 años); sino también respecto a la esfera laboral, donde se observa una fuerte disposición al trabajo «ahora estoy laburando más que antes. Todo por mi hijo. Antes hacía una changuita y no iba más» (Luciano, 20 años). De esta manera, la conformación de la familia propia constituye en las trayectorias juveniles un punto de inflexión, a través del cual se suscitan transformaciones incluso en la propia subjetividad, que se aprecia en los relatos como un alejamiento de «la calle».

- Fue lo mejor que me pasó, ser papá

- ¿En qué te cambió?

- Me cambió mucho porque yo, más allá que laburaba, andaba todo el tiempo en la calle. Después me junté y cuando decidí ser papá, yo decidí dejar todo, porque ya no es lo mismo, ya no salís más, tenés una responsabilidad con la familia (Mauricio, 24 años). 
Más aún, la transición hacia la familia de procreación adquiere un nuevo sentido al aprehender el proyecto futuro. Las expectativas de un mejor porvenir es una apuesta intergeneracional, donde el imaginario escolar aparece como un valor simbólico fundamental al otorgar la posibilidad de «ser alguien», de continuar una profesión y de alcanzar un título que permita acceder a un empleo de calidad. La esperanza de mejorar su posición de origen es así una apuesta que los jóvenes depositan en sus hijos, quienes representan tanto las expectativas de lograr la tan anhelada movilidad social, como también el deseo de que las nuevas generaciones no experimenten las mismas condiciones de privación (tipo ideal: trayectorias reproductivas).

- Al nene mío lo tengo así, estudiando... Que no salga como yo, que tengo casi 30 años y no tengo ningún laburo.

- ¿Qué proyectos te gustaría para él?

- Que tenga un laburo, que tenga una familia y que la tenga bien, no que tenga que andar changueando como yo en una cooperativa (Ramiro, 29 años).

\section{TRAYECTORIAS REPRODUCTIVAS: EL CASO DE DARÍO}

Darío es un joven de 26 años de edad. Sus abuelos se hicieron cargo de su crianza a una edad muy temprana y a sus 12 años decidieron radicarse en El Aluvión, por razones laborales. Así caracteriza al barrio este joven: «el barrio es tranquilo, conozco muchas personas de acá, somos todos amigos..., con la mayoría de los chicos me crié».

En relación a su trayectoria escolar, Darío no logró culminar los estudios primarios. Los vínculos que estableció con la institución educativa no se correspondieron con sus expectativas: «quería terminar los estudios. Después ya no pude con el tema de que tenía que laburar, dejé la escuela, dejé todo». En efecto, desde una temprana edad tuvo que asumir el papel de proveedor, a causa de un acontecimiento familiar: la enfermedad de su abuelo. Así, su primera ocupación fue a los 14 años de edad en una fábrica que hacía máquinas de aserradero: «él [abuelo] tuvo que dejar el laburo ese y no tenía quien lleve la plata, yo tenía que ayudar». Allí, estuvo durante cuatro años hasta que finalmente el establecimiento cerró. En seguida, ingresó en una pizzería y a continuación en una panadería, por un breve lapso temporal. Darío experimentó períodos de desocupación en variadas ocasiones, «arreglándosela» mediante una variedad de «changuitas» y movilizando sus redes sociales cercanas, a través de las cuales pudo acceder — «de boca en boca»— a trabajos esporádicos y, actualmente, llegar a ser oficial de albañilería. 
Hace ya seis años se independizó de la casa de sus abuelos, luego de pasar por un breve período cohabitando con sus suegros. Hoy en día, vive junto a su pareja en un terreno que consiguió comprar en «cuotas livianitas» con la ayuda de su primer «patrón». En una primera instancia, logró «plantar una casilla», quedándose a vivir allí; pero al momento de la entrevista se encontraba construyendo «de a poquito» la casa de material. Para este joven, el evento biográfico más significativo refiere a la conformación de su familia propia. Más aún, el retraimiento hacia la esfera privada del hogar deja atrás un período de sociabilidad juvenil frente a la actual vida conyugal: «cuando era chico, antes de estar en pareja, estuve mucho tiempo así en las calles... Conseguirla a mi señora y tener a los dos nenes, fueron los cambios más grandes... salí de la calle».

Por su parte, la centralidad que adquiere la esfera familiar se vislumbra también en relación al mundo del trabajo, donde este joven no establece ningún anhelo ocupacional: «voy a tener que laburar toda mi vida... Proyecto, yo pienso que no voy a llegar a ninguno». En el marco de un horizonte de oportunidades acotado, avizora como única salida la reproducción de las condiciones laborales actuales: «[albañilería] es muy pesado y hay muy poca plata..., pero otra no queda, no hay otra. Tenés que agachar la cabeza... Para darle de comer a mis hijos me alcanza». En este marco, adquiere primacía la búsqueda de un proyecto intergeneracional, que deposita en las nuevas generaciones la esperanza de un futuro mejor. Como expresa Darío en relación al porvenir de sus hijos:

Que no les falte nada. Quiero que terminen los estudios ellos, como yo no los terminé. Que el día de mañana sean algo, que estudien algo, que se reciban en algo y que no los agarre la calle, porque ahora la calle está muy jodida (Darío, 26 años).

\section{c) Marcas territoriales: el espacio barrial como dimensión constitutiva de las trayectorias juveniles}

La dimensión espacial cobra una relevancia particular en la construcción de las biografías juveniles, al desarrollarse un fuerte sentido de pertenencia hacia el ámbito barrial: «la ciudad es vivida desde el barrio. El territorio funciona como anclaje identitario desde el cual en parte se mira e interpreta el mundo» (Chaves, 2011:5). Esta identificación con el entorno barrial presenta una enorme incidencia sobre las prácticas cotidianas de los entrevistados, en especial, en lo que respecta a los circuitos urbanos que despliegan. En ese ámbito trascurren gran parte de su tiempo, al realizar sus actividades recreativas y for- 
mativas: concurren a la escuela, forman sus amistades e, incluso en varias oportunidades, el barrio se convierte en el lugar predilecto para el desarrollo de su trayectoria laboral.

Como espacio cercano e inmediato, el barrio constituye una escena privilegiada: representa el ámbito donde se producen los encuentros y las interacciones locales; asimismo, adquiere una relevancia particular en las experiencias y condiciones de vida para quienes asume la característica de lugar de trabajo. Si usualmente se representa al barrio desde su función residencial, esta afirmación no debe ocultar el hecho de que para muchos de sus habitantes cumple también un papel productivo. En un contexto de segregación espacial, las prácticas laborales se encuentran así — cada vez más - localizadas territorialmente: «yo acá en mi barrio, atiendo el negocio, estoy en mi casa» (Gastón, 18 años); «siempre agarro algún laburito por el barrio» (Darío, 23 años). La imposibilidad de traspasar los límites barriales configura un escenario de renovada fragmentación y desigualdad social.

No me puedo mover, no salgo de acá dentro, como dice mi hermana, del barrio no salgo. Lo único que conozco es el barrio... Me dice mi viejo: «nunca saliste del barrio, siempre estuviste acá, en la esquina y con tus amigos (Jeremías, 20 años).

La adscripción identitaria que despliegan los entrevistados en torno al ámbito barrial se refleja en las reiteradas frases «soy de acá», «es mi casa», donde el barrio aparece como un espacio de identificación e inscripción territorial: «desde que nací soy de acá, me crié en el barrio, ya como que vivo acá... bah, vivo acá pero ya como soy del barrio» (Germán, 18 años). Para la mayoría de estos jóvenes su historia residencial y la de sus padres comienza en El Aluvión, vislumbrando un futuro allí.

- Me quedaría acá yo, por siempre.

- ¿Por qué «por siempre»?

- Porque está re piola el barrio... tenés los amigos, ya conocés a todos, viste... ya te acostumbrás, además de chiquito viví acá (Marcelo, 17 años).

El espacio barrial presenta una enorme incidencia en las biografías juveniles como un ámbito de creación de amistades «acá tengo una banda de amigos» (Paco, 19 años), donde se tejen redes de carácter íntimo y familiar «nos conocemos todos acá» (Fermín, 19 años). En 
estas circunstancias, el entorno local comienza a cumplir funciones inéditas frente a las fallas producidas en otras modalidades de inscripción social (Merklen, 2005), convirtiéndose en el soporte privilegiado de nuevas solidaridades que implican el desarrollo de patrones de interacción e identificación vinculados al territorio y los grupos de pares. Como explica Reguillo:

...a partir de una crisis en las «instituciones intermedias», incapaces por distintos motivos de ofrecer certidumbres a los actores sociales, las culturas juveniles han encontrado en sus colectivos elementos que les permiten compensar este déficit simbólico, generando diversas estrategias de reconocimiento y afirmación, entre las que se destaca el uso de objetos, marcas y lenguajes (Reguillo, 2000:99-100).

La importancia que tiene el espacio urbano para los jóvenes se revela en las formas de percepción y apropiación del barrio, escenario donde emergen ámbitos de socialización y de generación de subjetividades desde los propios jóvenes. Allí, despliegan sus formas de sociabilidad entre pares, donde la música, la vestimenta y los lugares frecuentados aparecen como signos de una identidad compartida.

- ¿Qué haces en tu tiempo libre?

- Me quedo en la esquina. Me tomo una coca, me quedo fumando un cigarro, una marihuana. Me gusta divertirme, quedarme con los pibes, ahí tranquilo... Todos los días lo mismo, es como que algo me tiene atado. Estoy en la esquina y me quiero quedar ahí con mis compañeros (Jeremías, 20 años).

«La esquina» se presenta como el escenario de construcción de sociabilidades, lugar destinado para el encuentro con pares. Con el anochecer el espacio público se carga densamente de sentidos, funcionando como anclaje identitario de un conjunto de grupos juveniles que adoptan las esquinas como lugares de reunión, consumo y amistad: «son como treinta grupos acá en el barrio. Son una banda de pibes, pero cada uno tiene su grupito» (Jeremías, 20 años). Así, en el espacio barrial se desarrollan diversas estrategias de diferenciación entre grupos juveniles, que encuentran en los clivajes espaciales una forma de materialización.

— Nos juntamos siempre en... nosotros le decimos «el paredón», allá en 163

- ¿Qué hay ahí? ¿Una pared grande? 
- Sí, hay una pared grande, porque hay un predio ahí, de fútbol. Y paramos ahí... ya es lugar de nosotros porque ya le pusimos un banco, tiene las paredes dibujadas ...

- ¿Hay otros lugares así? ¿Otros grupos?

- Sí, pero nosotros nos juntamos entre nosotros. No nos juntamos con otros pibes. Nos hablamos con todos los del barrio, todo, pero la junta es esa, nadie más (Herlo, 16 años).

En el contexto de estudio se presenta un estilo juvenil propio de ese grupo sociocultural que se pone de manifiesto en prácticas vinculadas con la utilización del espacio público «la esquina», el consumo de un género musical particular (rap o cumbia) y la impronta de un vestuario «deportivo» (zapatillas con «resortes», viseras, piercings, cortes de pelo). Para este grupo de jóvenes, el vínculo con la actividad laboral reside en la disposición de ingresos que posibilite transitar por espacios de sociabilidad y expresión juvenil (tipo ideal: trayectorias territorializadas). Siguiendo a Guerra Ramírez, «el consumo permite a los jóvenes experimentar roles propios de su edad y responder a los imperativos sociales de relacionarse con 'otros' semejantes con los que se identifican y comparten las mismas prácticas y códigos culturales» (2008:173). Como relata Herlo, en sus primeros pasos por el mundo laboral:

[Trabajaba] para llegar al fin de semana y tener mi plata... Me la gastaba en boludeces, ni ropa me compraba, que sé yo, salía de joda... Me la gastaba en la esquina con los chicos, tomando alcohol... todo eso (Herlo, 16 años).

Este grupo de jóvenes se encuentra provisto de lazos barriales próximos y fuertes en torno a los cuales construye vías de integración alternativas a las tradicionales. Más aún, la escuela, el trabajo y la familia desaparecen como los principales referentes de articulación en la conformación de subjetividades. Por un lado, la familia de origen se revela como un ámbito conflictivo del cual las nuevas generaciones buscan diferenciarse, sin haber constituido aún su propio hogar: «estaba con mis amigos ahí [en la esquina], y me olvidaba de todo... de los problemas que tenía en mi casa» (Gastón, 18 años). Por otro, la institución educativa tampoco logra interpelar a estos jóvenes, entrando en tensión la retribución a largo plazo que promete la escuela con los ingresos inmediatos que provee el trabajo - aunque informal e inestable - para satisfacer necesidades propias de la edad. 
- La escuela, quiero terminar. Pero no quiero empezar el colegio porque no sé nada, y me va a costar trabajo terminar el colegio

- ¿Y por qué querés terminar?

- Quiero terminar para que tenga un buen oficio, y ahí dejo todo... así tengo una familia bien, no como algunos que tienen familia y viven así nomás, se drogan, le enseñan cosas feas a sus hijos. Yo al contrario quiero enseñarle lo bueno... lo que yo pasé que no lo pasen ellos, yo soy así, tipo una familia piola

- [Además...] en lo que yo quiero laburar tengo primero que terminar la escuela

- ¿De qué te gustaría laburar?

- De veterinario... si ahora quiero laburar, sí, agarro cualquier trabajo, de albañil, lo que venga. Pero más me gustaría trabajar de veterinario, ser algo... (Marcelo, 17 años).

En este último grupo, los relatos juveniles revelan la ausencia de proyectos con los cuales identificarse. Si bien el universo de lo deseable se representa de manera nítida y definida en lo que respecta a las condiciones laborales (importancia de un trabajo «fijo», «cómodo», «en blanco»); el universo de lo posible aparece asociado con imágenes de un futuro incierto o utópico. En este sentido, se efectúa un ajuste de las expectativas a las oportunidades que ofrece el medio, donde las ocupaciones precarias e informales son percibidas por los jóvenes como aquellas salidas laborales que están a su alcance. En un horizonte de inestabilidad duradera, el vínculo con el trabajo se orienta hacia el carácter instrumental y la idea de trabajar de «lo que venga», reduciéndose el espectro temporal de proyección y las posibilidades de desarrollar una subjetividad ligada al trabajo. Así, para estos entrevistados los planes se manifiestan por la tendencia a pensar en el porvenir como un proyecto utópico o, incluso, algunos jóvenes se encuentran imposibilitados para imaginar el futuro: «no sabría de qué me veo trabajando... no sé qué laburo, un laburo fijo» (Jeremías, 20 años).

\section{TRAYECTORIAS TERRITORIALIZADAS: EL CASO DE JEREMÍAS}

Jeremías es un joven de 20 años de edad, desde que nació vive en El Aluvión junto a sus tres hermanos y su padre, en una casa cercana al arroyo. Así expresa el significado que adquiere el barrio en su vida: «una casa, ya es mi barrio, de acá no me voy nunca, me voy a quedar acá hasta que me muera». El ámbito barrial se concibe para este joven como un espacio socializador desde la infancia, «acá tengo todos mis amigos». Esta prepon- 
derancia del entorno local se observa en su incidencia sobre otras esferas vitales. En el caso de la escuela, a los 17 años de edad abandona el 8vo año, luego de algunas repitencias: «por la vagancia en el barrio, por joda, por estar con los pibes». Sin embargo, decide retomar los estudios en un establecimiento lejano a su hogar: «allá no iba con nadie y me ponía a estudiar. Era la alternativa esa, porque si vengo acá sigo todos los días de joda».

En relación a la trayectoria laboral, no por un acontecimiento azaroso Jeremías comenzó a trabajar como ayudante de plomero. Su padre ejerció durante toda su vida ese oficio, hasta que un problema de salud le impidió continuar. Así, a los 15 años edad, ingresa al mundo laboral: «lo aprendí en mi casa, trabajando con él [padre]. Y después empecé a buscar un laburo, me dijo mi viejo que precisaba un amigo de él que era plomero y fui»; y continúa explicando: «salió el laburo y me gustó. Y más de plomero que me gustaba salir como mi viejo». Luego de un año, este joven abandona el trabajo y retoma sus estudios, culminando la educación básica. En ese momento posterior, transita por una variedad de ocupaciones informales: ayudante de mecánico, ayudante de albañil, ciruja y en un lavadero de autos. Como expresa el entrevistado: «trabajé en una banda de cosas... pero no trabajé un año, trabajé cosas... changuitas que hice». A todas estas actividades laborales accedió por medio de una amplia red de familiares y amigos.

En la actualidad, Jeremías se desempeña como cooperativista en un centro comunitario barrial. Este joven tiene una percepción negativa de dicha ocupación y quiere encontrar «un buen laburo». Sin embargo, la segregación espacial propicia una actitud pasiva frente a la búsqueda de nuevas redes sociales que garanticen el acceso a una ocupación por fuera del barrio: «no salgo de acá de El Aluvión, no me puedo mover... No puedo encontrar la manera de yo salir a la calle a buscar trabajo... capaz será por la viserita, por la vestimenta». Asimismo, el proyecto laboral asume en este entrevistado un carácter indefinido, sin alcanzarse una identificación con alguna ocupación: «cualquier laburo, mientras que me pague, que tenga un buen sueldo, te laburo de cualquier cosa». Más aún, su trayectoria se representa como un camino inexorable «ya me quedé en el pozo, una vida que nunca la voy a cambiar», que reafirma la centralidad del barrio y el grupo de pares en la conformación de su subjetividad.

Es un quilombo el barrio, todos los días peleas, tiros, joda. Una nube de pedo. Si sacarían la droga, esto sería todo concheto, todos caretitas, pero esto... todos indios. Acá en el barrio lo único que pensás es droga, joda y todo... estar con los pibes... El día que me vaya del barrio, capaz que sería otro pibe, cambiaría, pero no me voy de acá ni a palos (Jeremías, 20 años). 


\section{A MODO DE CONCLUSIÓN}

Durante las últimas décadas, se han producido transformaciones globales que, sin duda, han repercutido en las jóvenes generaciones. Estos cambios histórico-sociales trascienden al mercado de trabajo, involucrando otras instituciones sociales y dimensiones de la vida cotidiana de los sectores juveniles. Por esta razón, el artículo propone una mirada integral para comprender el modo en que se configuran los recorridos laborales en su imbricación con otras esferas vitales.

La perspectiva de las trayectorias constituye un marco de referencia fértil para dilucidar los procesos de construcción y reconstrucción de los itinerarios contemporáneos. Estos estudios procuran una aproximación procesual y dinámica, alejándose de los análisis que adoptan enfoques sincrónicos y/o destacan la linealidad de los rumbos biográficos. De esta manera, es una perspectiva privilegiada para indagar las transformaciones acaecidas en los itinerarios juveniles, al analizar las complejidades de su desestructuración, identificar sus formas típicas y aportar herramientas para su comprensión, iluminando las nuevas relaciones que las jóvenes generaciones mantienen con el mundo del trabajo y sus articulaciones con múltiples esferas de la vida.

En efecto, la pérdida de la idea de progreso, la imposibilidad de desarrollar un camino continuo en la vida laboral, el desdibujamiento de esquemas lineales y la obstrucción en la realización de una carrera, requiere de una aproximación que dé cuenta de las rupturas que caracterizan a las prácticas laborales juveniles contemporáneas. Desde este lugar, el conjunto de recorridos trasluce las incertidumbres de rumbos subsumidos en una dinámica discontinua, no acumulativa, donde el trabajo pierde sus rasgos de estabilidad, protección y previsibilidad.

Sin embargo, aunque el significado y las antiguas formas del trabajo tiendan a transformarse hacia un carácter instrumental en las experiencias de las nuevas generaciones, esto no significa que el trabajo pierda centralidad. Por el contrario, a lo largo del artículo vislumbramos que la actividad laboral constituye para los jóvenes una de las experiencias más significativas de la vida social. No obstante, esta primera afirmación necesita ser aprehendida desde una mirada integral que atienda los nuevos sentidos y prácticas que desarrollan los jóvenes en torno al trabajo, los cuales se orientan hacia un proyecto vital más amplio centrado en otros mundos de la vida: la escuela, la familia, el barrio y los grupos de pares. En el marco de un proceso de descentra- 
miento del mundo laboral, las trayectorias se tejen entre el universo de lo posible y lo deseable, visible en el modo en que las nuevas generaciones hacen frente a las restricciones de su medio y se apropian de sus horizontes de oportunidad.

A partir de estos sentidos extrínsecos, elaboramos una tipología en torno a las trayectorias de los jóvenes de El Aluvión, como recurso metodológico y analítico que permite vislumbrar la relación subjetiva de los jóvenes con la actividad laboral. La construcción de tipos ideales funciona como una herramienta heurística para comprender el modo en que se articulan y la incidencia que posee cada una de las esferas vitales en la configuración de diversas trayectorias. A los efectos del análisis, conformamos tres trayectorias típicas: la escolarizada, la reproductiva y la territorializada. La preponderancia que asumen estas distintas esferas, opera como un marcador fundamental en la configuración diversificada de los itinerarios juveniles, adquiriendo un carácter distintivo los sentidos y expectativas otorgadas al trabajo.

LA Plata (ARGENTINA), DiCIEMBRE 2014

RECIBIDO: SEPTIEMBRE 2015

ACEPTADO: NOVIEMBRE 2015 


\section{REFERENCIAS BIBLIOGRÁFICAS}

ChAVES, M. (2011): «Jóvenes entre el centro y la periferia de la ciudad, del Estado y de la academia». En CARPIO (comp.): Las políticas sociales urbanas y la construcción de ciudadanía. Buenos Aires: Paidós.

DE BARROLA, M. (2006): Formación escolar para el trabajo: posibilidades y límites. Experiencias y enseñanzas del caso mexicano. Montevideo: CINTERFOR/OIT.

FREYTES FreY, A. (2009): «En los bordes del trabajo: los sentidos subjetivos del trabajo para jóvenes varones y mujeres con inserción laboral precaria». $9^{\circ}$ ASET. Buenos Aires.

GoRZ, A. (1997): Metamorfosis del trabajo. Madrid: Sistema.

GUERRA RAMíREZ, M. I. (2008): «Trayectorias escolares y laborales de jóvenes de sectores populares. Un abordaje biográfico». Tesis de Doctorado. Cinvestav, México.

JACINTO, C. (2006): La escuela media. Reflexiones sobre la agenda de la inclusión con calidad. Buenos Aires: Santillana.

- (2010): La construcción social de las trayectorias laborales de jóvenes: políticas, instituciones, dispositivos y subjetividades, Buenos Aires: Teseo/IDES.

KeSSLER, G. (2010): Sociología del delito amateur. Buenos Aires: Paidós.

LONGO, M. E. (2012): «Las representaciones sobre el futuro: ¿un indicador de desigualdad de inserción laboral de los jóvenes?» En BATTISTINI y MAUGER: La difícil inserción de los jóvenes de clases populares en Argentina y Francia. Buenos Aires: Prometeo.

MARGULIS, M. (2008): La juventud es más que una palabra. Ensayos sobre cultura y juventud. Buenos Aires: Biblios.

MÁrqueZ, F. (2001): «Trayectoria de vida y trabajo en sujetos pobres». Proposiciones $\mathrm{N}^{\circ} 32$. Santiago: Ediciones SUR.

Merklen, D. (2005): Pobres ciudadanos. Las clases populares en la era democrática. Buenos Aires: Gorla.

PRIES, L. (1999): Conceptos de trabajo, mercados de trabajo y proyectos biográficos laborales. México: Mimeo.

REguillo, R. (2000): Emergencia de culturas juveniles. Estrategias del desencanto. Bogotá: Norma.

RIFKIN, J. (1996): El fin del trabajo. México: Paidós.

SARAVÍ, G. (2009): Transiciones vulnerables: juventud, desigualdad y exclusión en México. México: CIESAS.

Svampa, M. (2000): Desde abajo. La transformación de las identidades sociales. Buenos Aires: Biblos.

Tenti FAnfani, E. (Comp.) (2000): Una escuela para los adolescentes. Reflexiones y valoraciones. Buenos Aires: UNICEF/Losada. 